\title{
Communication with a Special Emphasis on Intercultural Communication
}

\author{
Raholanda White \\ Middle Tennessee State University
}

Chinese students' and United States students' learning styles are influenced by culture. This involves how their parents raised them, their educational backgrounds, their life experiences and their entire frame of reference, which includes all of the above mentioned components.

This article makes a comparative study of intercultural communication between Chinese students and American students about the ways they communicate in similar and different ways when it comes to cross cultural communication

Keywords: American, China, Chinese Students, United States, United States Students, Business Communication, Culture, Intercultural Communication, Cross-Cultural Communication, Guangxi University Teaching Experience, Middle Tennessee State University

\section{BACKGROUND}

In 2016 I returned to Guangxi University the second consecutive year to teach at Middle Tennessee State's partner university in Nanning, China, as a part of the MTSU-GXU established 2+2 program. Again I taught sophomore finance majors Business Communication. I was once again interested in intercultural communication as far as the Chinese students were concerned. I was also interested in United States students' perceptions and knowledge of intercultural communication as well and wanted to learn of similarities and differences between the two cultures.

The Chinese students' behavior and attitude were very similar to those in the first class I taught in 2015. These students too were quiet and very respectful when it came to classroom comportment. They did not volunteer to participate very often in class due to their culture. However, I did get several students to open up and begin to participate before the semester ended. A few of the young ladies shared with me that they were very shy.

Additionally, during the summer of 2016 I administered some assessments when teaching Chapter Four on Communicating A Cross Cultures (see the appendix). These were summarized and compared to assessments of the same nature that were administered in Business Communication in the fall 2016 to face-to-face students in Business Communication (BCED 3510) in the United States. 


\section{INTRODUCTION}

As an American faculty member teaching Business Communication in a Chinese classroom, I learned many different things about the learning styles of Chinese students. First, Chinese students are extremely quiet in the classroom. They usually do not ask questions during class, but rather after class. Second, they are very shy and are accustomed to faculty members lecturing while they just listen without interruption. This is certainly different for American students when it comes to learning in higher education.

Third, Chinese students' culture dictates that if you interrupt a professor, you are being disrespectful, where as in the United States we teach students to ask questions and become engaged during the lecture. According to a Chinese colleague, there is an old saying that says, "Once my teacher then my father, or once my teacher then my mother." That statement expresses how much Chinese students respect their teachers. This knowledge acquired from a colleague speaks volumes about the Chinese culture.

Lastly, United States students are taught to question teachers and make sure they understand the material while it is being taught and to be engaged in team work as a part of their learning experience. When I teach Chinese students, I always assign a group project to give them an opportunity as well as experience to interact with their peers.

To reiterate my previous statements about Chinese culture in the classroom, (Aguinis \& Roth, 2003, stated in Perreault, 2008) mentioned that a typical situation for a Chinese classroom would include an instructor reading from a script and not ever requesting, or expecting, student input. Limited application exercises are mandatory, while memorization of specific material from the textbook is highly encouraged.

\section{LITERATURE REVIEW}

China and some Asian as well as middle eastern countries have been identified as high-context cultures, while western countries like the United States, Canada, and Spanish-speaking countries are known to be low-context cultures. High-context cultures tend to practice collectivism, while low-context cultures thrive on individualism. These are certainly major cultural differences between China and most Western countries (Mao and Qian, 2015).

In low-context cultures, individuals tend to deliver communications more clearly and directly. The basic meaning lies in the communicated messages themselves. In contrast, high-context communication uses "more implicit and indirect messages in which meanings are embedded in the person or in the sociocultural context" Gudykunst et al., 1996, p. 511, (cited in Jingzi, Wenzhong \& Dimond, 2016).

As the world continues to become more globalized, Jingzi, Wenzhong \& Dimond, 2016, said that economic globalization and universal business exchanges are becoming progressively common. International economic activities are steadily being impacted by the intercultural communication competence of today's businessmen and women. Consequently, we need to expand the cultivation of intercultural assurance in business education programs.

\section{Teaching Intercultural Communication}

Educating for the purpose of developing intercultural abilities and not for the purpose of conveying information has insufficient consequences. As we know, the layout and dissemination of knowledge in classes has been changing, and some classes are now similar to training sessions; there is (or there should be) less weight put on theory and more focus on real-world learning. Additionally, the final grade is a reflection of the student's (or trainee's) abilities and experiences, rather than a measure of the extent to which he or she has internalized theories or descriptions of beliefs (Chiper 2015).

Chiper 2015 also states that when preparing to teach intercultural communication, the learning does not occur only between professionals with different countries of origin, as wide apart as the United States and Japan. Therefore, we should consider using the adjective "intercultural" to label interactions among professionals from bordering countries, or from the same country, coming from different ethnic backgrounds, among which differences are not fundamental but gradual. At the same 
time, what distinguishes them is not only race or origin, but also their occupation, gender, age, and life experience. Consequently, every person inhabits different dialects and sociolects, and professional jargons, which make professional communication in the global economy to be an essentially inter-discursive communication, as Scollon and Scollon (2001), argued in their book Intercultural Communication: A Discourse Approach (cited in Chiper 2013).

\section{Contemporary Developments in a Globalized Workplace}

According to Fay, Prahalad, and Mingsheng, 2011, due to present-day trends such as air transportation and population shifts, as well as technological improvements like the World Wide Web, blogs, and global virtual networks, intercultural communication challenges have become more obvious.

Moreover, current trends in population shifts suggest that push-and-pull-factors in the global economy directly and indirectly influence the degree of global workforce mobility. Push factors may be described as wars, poverty, natural disasters and ethnic conflict that unfortunately force individuals to uproot and seek other more secure places to live, study, and work. Consequently, pull factors include better quality of education, job opportunities, peace, and prosperity which bring people of different cultures, religious, and political persuasions into the same global workplace arena (Fay, Prahalad, and Mingsheng, 2011).

As a faculty member in the twenty-first century, it is imperative to experiment with new ways of teaching by thoroughly expressing what we mean when teaching a classroom of diverse students. Not only in China but just as recently as Thursday, April $11^{\text {th }}, 2019$, students in my Business Communication class were taking an exam and two American students and students from Spain and Vietnam asked me what did "alleviate" mean, which was a word used in one of the short-answer essay questions. It was interesting to me concerning the American students' vocabulary. The behavior of the international students did not surprise me because that is how my Chinese students have behaved during an exam if the test is objective.

\section{Purpose of the Study}

The purpose of the study was to compare how Chinese students and United States students differ in terms of intercultural communication and how they communicate in similar and different ways cross culturally.

\section{Research Design}

The researcher used three inventory assessments to collect data from students in the United States and China. A Manova and some descriptive statistics were used for the study (see the appendix).

\section{DATA COLLECTION PROCEDURES AND ANALYSIS}

\section{Participants}

Ethnicities represented in this study included Caucasians ( 6 females, 10 males), Middle Easterners (5 males), Asians (1 male), Latin Americans (2 males), African Americans (2 females), and Chinese (28 females, 17 males). The Chinese students were sophomore finance majors. The Caucasians, Middle Easterners, Asians, and Latin American students were either business majors, communication majors, electronic media and aerospace majors. The Chinese students were enrolled at Guangxi University in Nanning, China. The African Americans, Caucasians, Middle Easterners, Asians, and Latin American students were enrolled at Middle Tennessee State University in the United States.

RQ1: Is there a statistically significant difference between the independent variables (United States students and Chinese students) and their effect on the six dependent variables? Six dependent variables: Personal Identity Score, Social Identify Score, Polychronic Time Frame, Monochronic Time Frame, Ethnocentrism Score, and Tolerance of Ambiguity Score. 
RQ2: Which one of the dependent variables is affected by the independent variables?

RQ3: Which independent variable mean score is better - that of the United States students or the Chinese students on two dependent variables: Personal Identity Score (PIS) and Polychronic Time Frame (PTF)?

\section{Findings}

RQ1: The multivariate showed that there is a statistically significant difference between the United States students and Chinese students on the six dependent variables simultaneously.

RQ2: There is a statistically significant difference between the dependent variables Personal Identity Score (PIS) and Polychronic Time Frame (PTF) and the independent variables.

RQ 3: There is a statistically significant difference between the independent variables (United States students in comparison with the Chinese students) mean scores on two dependent variables (Personal Identity Score (PIS) and Polychronic Time Frame (PTF).

\section{CONCLUSIONS}

1. Chinese students are less social than those from the United States. This is because the Chinese culture is quite reserved and students are very quiet and very polite. The Chinese students have high respect for their teachers on all levels. Students would interact among themselves to a certain extent, but students were quite reserved. When it was time to reconvene the class after break, students would usually assemble on time or once I informed them it was time to continue with the class.

2. Chinese students are not accustomed to interrupting their professors when they are lecturing. They are used to listening and asking questions after the professor finishes talking to the class. They believe it is rude to ask the professor questions while he or she is speaking to the class because this is what they have been taught. Students would come up to me after class and ask questions. It let me know that they did not feel comfortable asking questions during class.

3. The study also showed that most Chinese students felt that their unique self was not as important to them as their ethnic or cultural self. These students take a lot of pride in their country and are overall very loyal to their culture.

4. The study also showed that the United States students had a higher mean score than the Chinese students did as far as Polychronic Time Frame was concerned. Therefore, the United States students had more polychronic time tendencies than the Chinese students did.

\section{RECOMMENDATIONS}

1. The researcher recommends faculty disseminate as much information as possible about crosscultural communication to twenty-first century students. Since students from different cultures will interact with each other, they should know as much as possible about communicating with other cultures.

2. The researcher also recommends that students in Business Education classes become involved in classroom activities that focus on cross cultural-communication. Some of these activities may include researching other cultures, watching videos, and problem solving through case studies.

3. The researcher also recommends sharing pertinent information in the classroom with students about studying abroad or becoming involved in exchange programs. Visiting and studying in other countries is vital to today's students. 
4. The researcher recommends that faculty study and/ or teach in exchange programs in order to understand different cultures and ethnicities in the twenty-first century classroom. It is also vital to become involved in international, national, state, and local organizations.

5. Additional recommendations include building a network with faculty from other colleges and universities in order to keep the communication and networking opportunities current. These individuals may be in or out of the United States.

6. Researching in other countries, as this study did, will certainly help faculty and students when shared in the classroom learn more about other cultures. Professors planning to visit universities in other countries should consider conducting research while there.

\section{SUMMARY}

The research results from this study have confirmed that Chinese students are very loyal to their culture and that they are inclined to be more monochronic than United States students. This study verified that United States students exhibited more polychronic tendencies. As we know, sometimes the twentyfirst century student does not value time commitments as much as Baby Boomers or other generations. As an American faculty member, working, interacting, and observing Chinese students and faculty in China for two consecutive summers, I observed that they appeared definitely to be more loyal to their culture than Westerners. Additionally, from establishing a professional/social network with faculty members in the Guangxi University School of Business and International College, I certainly perceived how dedicated they were when it came to provide their students with the highest quality of education both in and out of the classroom.

Faculty from Guangxi University spend a lot of time teaching, researching, and providing service to their university and community as do professors from the United States. Chinese professors are very serious and work hard to ensure that a good learning environment is provided for all students.

As previously stated, I have built a professional/social network and good friendships with some members of the university's faculty. Because I enjoy teaching respectful Chinese students and working with faculty from Guangxi University, I plan to return to China and Guangxi University in the summer of 2019 to once again teach Business Communication to sophomore finance majors. It will be interesting to compare and contrast the students from summers 2015 and 2016 to the students of summer 2019. I am anticipating having my best students ever during this third teaching/learning experience. Students in the summer of 2016 class spoke better English than the first class of students I taught in 2015. I expect to see continued improvement in their English skills this coming summer.

Also, I have adjusted to the Chinese culture when it comes to teaching students Business Communication. For example, I have learned to speak slowly and to write on the board so that students can see exactly what I am explaining. Although these students are bilingual, they still need time to mentally translate what I say. The more examples I can provide about a specific concept the easier the learning process is. So, adjustment is key on my part as well.

Faculty development is a large part of an educator's career path. Every year we must strive to improve our professional growth in as many ways as possible, because learning is a life-long domestically. However, I believe when receiving the opportunity to work and learn about other cultures presents itself as this one has through Middle Tennessee State University, faculty should take advantage of the opportunities to acquire more knowledge in order to adequately teach the twenty-first century student regardless of country of origin.

Since I've had several opportunities to study and teach in Brazil (studied the Afro-Brazilian culture in summer 2012 in Salvador, Bahia, Brazil) as well as in China, I have grown both academically as well as professionally. I always share with my students that travel is one of the best ways to become educated about other cultures and to acquire knowledge in general. The example I often use is that if they were to travel to Chattanooga, Tennessee, which is about two hours from Middle Tennessee State University, they would learn something different and interesting from what they already knew about that city. 
In brief, studying and teaching abroad have been tremendous opportunities and valuable learning experiences of a lifetime for me. I would encourage faculty members in their perspective educational institutions to consider experiencing both or at least one of the opportunities. Also, Fulbright Scholarships are also available at most universities for either teaching and/or researching.

Through these invaluable learning opportunities, a teacher expands horizons and becomes so much better both personally and professionally.

\section{REFERENCES}

Chiper, S. (2013). Teaching intercultural communication: ICT resources and best practices. ProcediaSocial and Behavioral Sciences, 93, 1641-1645. Retrieved from www.scienceDirect.com

Fay, P., Prahalad, S., \& Mingsheng, Li. (2011). Intercultural Communication: Building a Global Community. Thousands Oaks, CA: Sage Publication, PVt.Ltd. e-Book. Chapter: Intercultural Communication in the Global Workplace.

Jingzi, D., Wenzhong, Z., \& Dimond,E.E. (2016). The Integration of Intercultural Business Communication Training and Business English Teaching, 9(2), 77-83

Mao, Y., \& Qian, Y. (2015). Facebook Use and Acculturation: The Case of Overseas Chinese Professionals in Western Countries. International Journal of Communication, 9, 2467-2486.

Perreault, H. (2008). Helping Chinese Students Adjust to U.S. Higher Education. Journal for Global Business Education, (pp. 20-27). 


\section{APPENDIX}

TABLE 1

GLM: SIS PIS MTF PTF ES TAS

COUNTRY (US VS CHINA)

\begin{tabular}{|c|c|c|c|c|c|}
\hline \multicolumn{6}{|c|}{ Between-Subjects Factors } \\
\hline & & Value Label & $\mathrm{N}$ & & \\
\hline \multirow[t]{2}{*}{ Country } & 1 & US & 26 & & \\
\hline & 2 & China & 45 & & \\
\hline \multicolumn{5}{|c|}{ Descriptive Statistics } & Statistics \\
\hline & Country & Mean & Std. Deviation & $\mathbf{N}$ & $\mathbf{F}$ \\
\hline \multirow[t]{3}{*}{ OddC_SIS } & US & 14.5385 & 2.88764 & 26 & US+ China \\
\hline & China & 13.7556 & 1.79843 & 45 & $\begin{array}{ll}17.880 \quad .000\end{array}$ \\
\hline & Total & 14.0423 & 2.27054 & 71 & $\begin{array}{ll}7.410 \quad .008\end{array}$ \\
\hline \multirow[t]{3}{*}{ EvenC_PIS } & US & 15.7692 & 2.30318 & 26 & US + China \\
\hline & China & 13.3111 & 2.39148 & 45 & \\
\hline & Total & 14.2113 & 2.62904 & 71 & Computed using alpha $=.05$ \\
\hline \multirow[t]{3}{*}{ OddF_MTF } & US & 11.1538 & 2.96233 & 26 & \\
\hline & China & 11.4667 & 2.34133 & 45 & \\
\hline & Total & 11.3521 & 2.56959 & 71 & \\
\hline \multirow[t]{3}{*}{ EvenF_PTF } & US & 16.1538 & 2.58754 & 26 & \\
\hline & China & 14.6667 & 1.97714 & 45 & \\
\hline & Total & 15.2113 & 2.31711 & 71 & \\
\hline \multirow[t]{3}{*}{ OddE_ES } & US & 13.5769 & 2.28338 & 26 & \\
\hline & China & 14.0222 & 2.07243 & 45 & \\
\hline & Total & 13.8592 & 2.14673 & 71 & \\
\hline \multirow[t]{3}{*}{ EvenE_TAS } & US & 13.0385 & 2.06844 & 26 & \\
\hline & China & 12.8889 & 1.86136 & 45 & \\
\hline & Total & 12.9437 & 1.92641 & 71 & \\
\hline
\end{tabular}



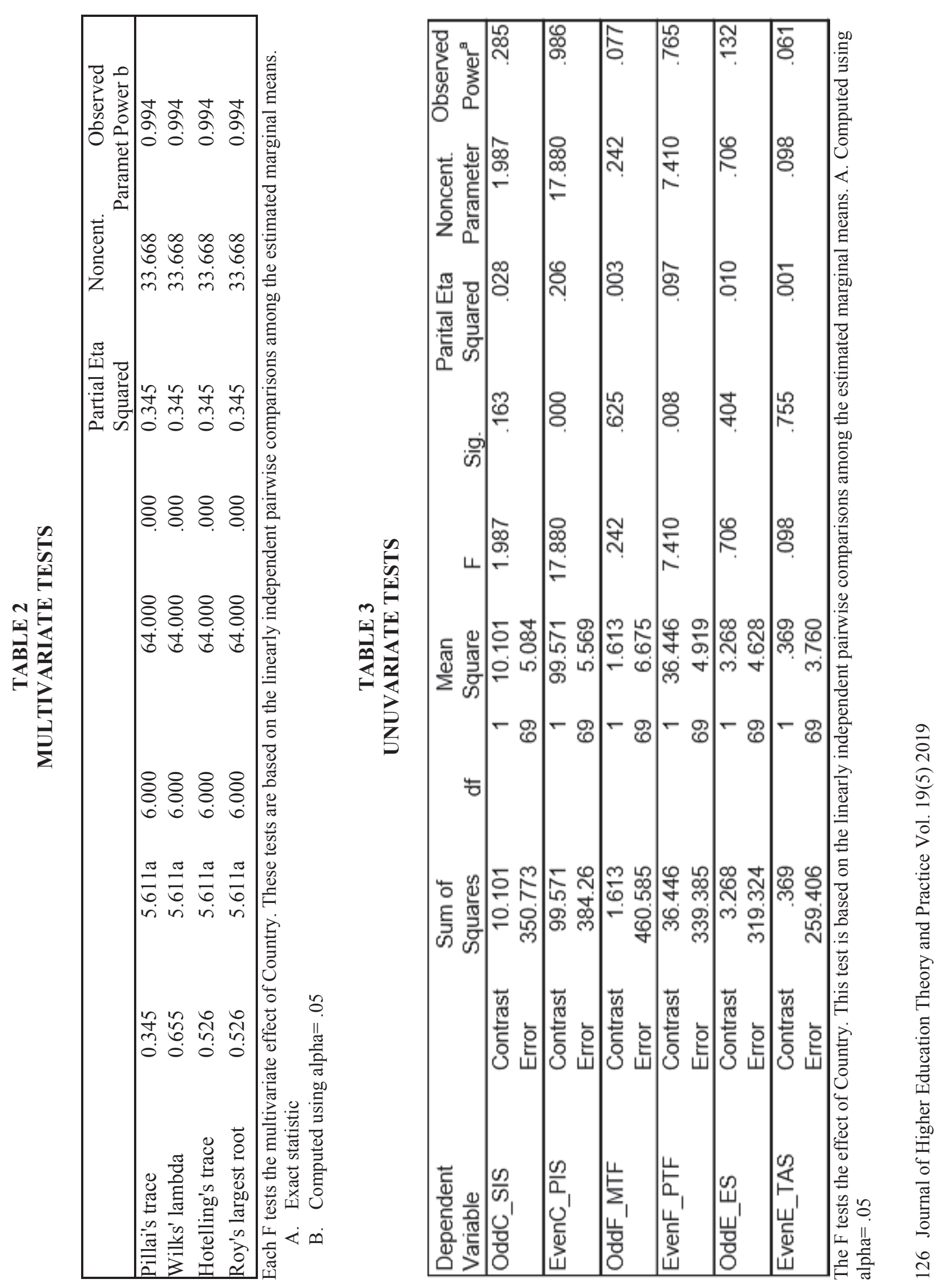


\section{ASSESSMENT NUMBER 1 ASSESSING THE IMPORTANCE OF YOUR SOCIAL AND PERSONAL IDENTITIES}

Instructions: The items below describe how people think about themselves and communicate in different situations. Let your first preference be your guide and circle the number in the scale that best reflects your overall value. The following scale is used for each item:

$1=\mathrm{SD}=$ Strongly Disagree

$2=\mathrm{MD}=$ Moderately Disagree

$3=\mathrm{MA}=$ Moderately Agree

$4=\mathrm{SA}=$ Strongly Agree

1. My group memberships (e.g., ethnic or gender) are

SA important when $\mid$ communicate with others.

2. My personality usually comes across loud and clear when I communicate.

3. I am aware of my own ethnic background or social roles when I communicate.

4. My personality has a stronger influence on my everyday interaction than any social roles.

5. I am aware of ethnic or gender role differences when I communicate.

6. I tend to focus on the unique characteristics of the individual when $\mid$ communicate.

7. I tend to focus on the unique characteristics of the individual when I communicate.

8. I believe my personal identity is much more important than any of my social membership categories.

9. If people want to know me, they should pay more attention to my professional or student role identity.

10. My unique self is more important to me than my ethnic cultural role self

$\begin{array}{cccc}\text { SA } & \text { MA } & \text { MD } & \text { SD } \\ 4 & 3 & 2 & 1 \\ 4 & 3 & 2 & 1 \\ 4 & 3 & 2 & 1 \\ 4 & 3 & 2 & 1 \\ 4 & 3 & 2 & 1 \\ 4 & 3 & 2 & 1 \\ 4 & 3 & 2 & 1 \\ 4 & 3 & 2 & 1 \\ 4 & 3 & 2 & 1 \\ 4 & 3 & 2 & 1\end{array}$

Scoring: Add up the scores on all the odd-numbered items and you will find your social identity score. Social identity score: ___ Add up the scores on all the even-numbered items and you will find your personal identity score. Personal identity score:

Interpretation: Scores on each identity dimension can range from 5 to 20; the higher the score, the more social and/or personal you are. If all the scores are similar on both identity dimensions, you emphasize the importance of both social and personal identities in your everyday communication process.

Reflection Probes: In the first encounter with a stranger, do you usually try to understand the social role identity or personal identity of the stranger? Why? Do you primarily share your social role identity or personal role identity information with a stranger? What facors (e.g., work situations, classroom situations, or attraction? Usually prompt exchange either more social role data or more personal identity data in your communication process?

Ting-Toomey, S., \& Chung, L. C. (2012). Understanding Intercultural Communication (2"9 ed.). New York, Oxford University Press, Inc. With permission from the authors, Dr. Stella Ting-Toomey and Dr. Leeva Chung, for educational classroom use only. 


\section{ASSESSMENT NUMBER 2 ASSESSING THE IMPORTANCE OF YOUR SOCIAL AND PERSONAL IDENTITIES}

Instructions: Recall how you generally feel and act in various situations. Let your first preference be your guide and circle the number in the scale that best reflects your overall impression of yourself. The following scale is used for each item:

$1=$ NO! $=$ Strongly Disagree-IT'S NOT ME!

$2=$ no $=$ Moderately Disagree-it's kind of not me

$3=$ yes $=$ Moderately Agree-it's kind of like me

4=YES!=Strongly Agree-IT'S ME!

1. Time is not necessarily under our control.

2. It's very important for me to stick to a schedule.

3. I'm very relaxed about time.

4. Meeting deadlines is very important to me.

5. Unexpected things happen all the time-just flow with it.

6. I get irritated when people are not on time.

7. It's OK to be late when you're having a wonderful conversation with someone.

8. I like to be very punctual for all my appointments.

9. I'm more concerned with the relationship in front of me than clock time.

10. I keep an appointment book with me all the time.

$\begin{array}{cccc}\text { SA } & \text { MA } & \text { MD } & \text { SD } \\ 4 & 3 & 2 & 1 \\ 4 & 3 & 2 & 1 \\ 4 & 3 & 2 & 1 \\ 4 & 3 & 2 & 1 \\ 4 & 3 & 2 & 1 \\ & & 2 & 1 \\ 4 & 3 & 2 & 1 \\ 4 & 3 & 2 & 1 \\ & & 2 & 1 \\ 4 & 3 & & \\ 4 & 3 & 2 & 1\end{array}$

Scoring: Add up the scores on all the odd-numbered items and you will find your monochromatic-time preference score. Monochromatic-time preference score: Add up the scores on all the even-numbered items and you will find your polychronic-time preference score. Polychronic-time preference score:

Interpretation: Scores on each identity dimension can range from 5 to 20; the higher the score, the more monochronic and/or polychronic time tendencies you have. If the scores are similar on both time dimensions, you are a bichronemictime communicator.

Reflection Probes: Take a moment to think of the following questions: Do you like your monochronic and/or polychronic time tendencies? Why or why not? Where do you learn your sense of time or clock rhythms? How do you think you can deal effectively with people who have a very different time preference from you?

Ting-Toomey, S., \& Chung, L. C. (2012). Understanding Intercultural Communication (2nd ed.). New York, Oxford University Press, Inc. With permission from the authors, Dr. Stella Ting-Toomey and Dr. Leeva Chung, for educational classroom use only. 


\section{ASSESSMENT NUMBER 3 PROBING YOUR ETHNOCENTRIC TENDENCIES}

Instructions: The following items describe how people generally think about themselves and their cultural groups. Let your first preference be your guide and circle the number in the scale that best reflects your overall agreement with the statement. The following scale is used for each item:

$1=$ NO!=Strongly Disagree-IT'S NOT ME!

$2=$ no $=$ Moderately Disagree-it's kind of not me

$3=$ yes $=$ Moderately Agree-it's kind of like me

4=YES!=Strongly Agree-IT'S ME!

Generally speaking...

1. I believe my culture offers the best lifestyles

SA compared with other cultures.

2. I like routines and a stable environment.

3. My culture is very advanced in comparison with other cultures.

4. I don't like ambiguous or uncertain situations.

5. My culture provides the best opportunity for its members to achieve their goals.

6. I get very stressed in unfamiliar settings.

7. My cultural group has the most expressive language and vocabulary.

8. I don't like to approach strangers for anything.

9. My culture has a very rich history and traditions.

10. I get quite intimidated thinking of living in another country.
4

4

4

4

4

4

4

4

4

4

MA
3
3
3

$\begin{array}{cc}\text { MD } & \text { SD } \\ 2 & 1 \\ 2 & 1 \\ 2 & 1\end{array}$

3

$\begin{array}{ll}2 & 1 \\ 2 & 1\end{array}$

3

3

$$
\begin{aligned}
& 3 \\
& 3
\end{aligned}
$$

3

3

3
1

1

1

Scoring: Add up the scores on all the odd-numbered items and you will find your ethnocentrism score. Ethnocentrism score: __ . Add up the scores on all the even-numbered items and you will find tolerance of ambiguity score. Tolerance of ambiguity score:

Interpretation: Scores on each identity dimension can range from 5 to 20; the higher the score, the more ethnocentric and/or intolerant of ambiguity you are. If all the scores are similar on both attitude dimensions, you are high on cultural ethnocentrism and high on your fear of ambiguous situations.

Reflection Probes: Take a moment to compare your scores with a classmate's. Think of the following questions: Where did you learn your attitudes about your own culture and its value compared with other cultures? What fears do you have in approaching new or unfamiliar situations? Why? How do you think you can prepare yourself more effectively in dealing with new cultural situations and cultural strangers?

Ting-Toomey, S., \& Chung, L. C. (2012). Understanding Intercultural Communication (2nd ed.). New York, Oxford University Press, Inc. With permission from the authors, Dr. Stella Ting-Toomey and Dr. Leeva Chung, for educational classroom use only. 